\title{
Adherence counseling during patient contacts in Swiss community pharmacies
}

\author{
This article was published in the following Dove Press journal: \\ Patient Preference and Adherence \\ 24 April 2015 \\ Number of times this article has been viewed
}

\section{Fabienne Boeni \\ Isabelle Arnet \\ Kurt E Hersberger}

Pharmaceutical Care Research Group, Department of Pharmaceutical Sciences, University of Basel, Basel, Switzerland
Correspondence: Fabienne Boeni Pharmaceutical Care Research Group, Department of Pharmaceutical Sciences, University of Basel, Klingelbergstrasse 50, $\mathrm{CH}-4056$ Basel, Switzerland

Tel +4I 6I 267 I5 29

Fax $+4|6| 267$ |4 26

Email fabienne.boeni@unibas.ch
Purpose: Numerous studies showed the effectiveness of pharmaceutical care in improving medication adherence in primary care patients. However, in daily pharmacy practice, the provision of pharmaceutical care appears to be limited. We aimed at quantifying the content of counseling by community pharmacy staff during patient contacts, especially adherence counseling, and at investigating pharmacist views about their practice of adherence counseling.

Patients and methods: A Master's student in Pharmacy observed patient contacts at selected community pharmacies in the region of Basel, Switzerland. Content of counseling was manually ticked on a checklist with predefined themes (administration, dose, effect, and adherence). Pharmacists working in the pharmacy were interviewed on triggers, topics, and barriers in adherence counseling.

Results: In 20 community pharmacies and during a total of 148.1 hours, 1,866 patient contacts were observed. During the 1,476 patient contacts including the dispensing of one or more medications, counseling was provided to 799 (54.1\%) patients; with $735(49.8 \%)$ patients counseled about administration, 362 (24.5\%) about dose, 267 (18.1\%) about effect, and 99 (6.7\%) about adherence. Significantly more patients received counseling when they obtained prescribed versus over-the-counter medication $(P=0.002)$, a new prescription versus a repeat prescription $(P<0.001)$, or when they were served by a pharmacist versus by another staff member $(P<0.001)$. Of the 33 interviewed pharmacists, all except one reported actively approaching patients for adherence counseling. Triggers included medication-related and patient-related factors. The pharmacists named predominantly product-centered topics of adherence counseling. The most cited barriers were rejection of counseling by the patient and lack of time.

Conclusion: Half of the patients receiving one or more medications were counseled, and only $6.7 \%$ of all contacts included adherence counseling. Future studies should clarify how barriers to adherence counseling at the community pharmacy can be overcome.

Keywords: pharmaceutical care, community pharmacy, medication adherence

\section{Introduction}

Pharmaceutical care has been defined as "...the pharmacist's contribution to the care of individuals in order to optimize medicines use and improve health outcomes," and the pharmacist has been designated as part of the health care team for added value in the health care system. ${ }^{2-4}$ Pharmaceutical care activities practiced by community pharmacies have been shown effective in improving medication adherence. ${ }^{5-12}$ Faceto-face counseling during dispensing of medication is part of pharmaceutical care. ${ }^{4}$ Counseling can include providing education to patients (eg, about therapy, their condition), intervening in a patient's drug therapy (eg, optimizing intake times), and ultimately, helping improve medication adherence. ${ }^{13}$ Previous studies reported significantly improved adherence and persistence through targeted counseling by community pharmacists. ${ }^{14-16}$ 
Counseling practice in community pharmacies has been reported to be limited. In a pan-Europe comparison in 2009, the mean total score of pharmaceutical care provision, expressed as a percentage of the total score achievable, ranged from $31.6 \%$ to $52.2 \% .{ }^{17}$ Patient counseling was reported to be only a minor task in every day practice in the community pharmacy, ${ }^{18-21}$ and communication was predominantly nonmedical or product-centered, instead of patient-centered. ${ }^{22-24}$

At the dispensing of prescription medication, Swiss pharmacists are reimbursed for providing counseling on dose, frequency, administration, duration of use, storage, and potential adverse effects. ${ }^{25}$ Introduced in 2005, this was the first acknowledgment of cognitive services delivered by community pharmacists to improve the patients' use of medication. Additionally, the provision of a dose-dispensing aid by the pharmacy is reimbursed. ${ }^{26}$

To our knowledge, the current counseling practices in Swiss community pharmacies have not yet been addressed, especially the content of adherence counseling. The aim of this study was to quantify the content of counseling by community pharmacy staff during patient contacts, with a specific focus on adherence counseling, and to investigate the views of community pharmacists about their practice of adherence counseling.

\section{Material and methods}

Of 106 community pharmacies in the region of Basel, Switzerland, community pharmacies that had participated in previous studies ${ }^{27,28}$ were approached consecutively, according to a random number list, until the sample size of 20 was reached. This number was calculated to enable approximately 2,000 patient contacts, assuming that counseling would take 5 minutes and one investigator could observe approximately 100 patients during 8 hours. We did not perform analysis of health communication between pharmacy staff and patients, but rather, we observed and quantified the content of counseling. A Master's student in Pharmacy observed the patient contacts of the pharmacy staff in sequential order during 1 day at each pharmacy. The observation began at the entrance of one patient into the pharmacy and lasted until the departure of this patient; thereupon, the student observed the next patient who entered the pharmacy. Information about the staff member serving the patient, the number of dispensed medications, and content of counseling were manually ticked on a checklist. The checklist enabled ad hoc coding of the patient contacts by allocation into two categories ("medication on prescription" and "medication over the counter"), as well as the coding of four themes ("administration", "dose", "effect", and "adherence") and 12 topics of adherence counseling. The latter were deduced from published recommendations (Table 1). ${ }^{29}$ Observation time and characteristics of the pharmacy and the team were simultaneously assessed. At the end of the observation time, an interview was performed with all present pharmacists, consisting of two closed-ended questions (active approach to patients about adherence [yes/no]; frequency of active approach per month) and three open-ended questions (triggers, topics, and barriers in adherence counseling).

We defined explicit adherence counseling as provision of patient-centered information that directly addresses the spectrum of adherence problems, including unintentional (ie, the patient is physically or cognitively unable to adhere) and intentional nonadherence (ie, the patient is not willing to adhere); this included the use of targeted questioning ("have you missed any pills in the past week"), offer of refill reminders and dose-dispensing aids, reinforcement, etc. ${ }^{29}$ We defined implicit adherence counseling as provision of product-centered information, eg, information on administration or dose. This information does not directly address adherence but might prevent unintentional nonadherence.

Coded patient contacts were quantified and analyzed statistically within the sample of patients obtaining one or more medications. Answers from the interviews were categorized and analyzed quantitatively. We used SPSS V. 20 (IBM Corp., Armonk, NY, USA) for Windows for descriptive and comparative ( $\chi^{2}$-test) calculations. A $P$-value of $\leq 0.05$ was considered statistically significant. Missing data were excluded from analysis.

\section{Results}

During February and March 2010, 21 community pharmacies were approached, 20 took part in the study, and one pharmacy declined participation without specification of a reason. The pharmacies were located in the city center (eight), in residential districts (eight), and in shopping centers (four). Of a median of 9.25 opening hours (range 8.75-11.5), 7.5 hours (range 6.5-7.75) were observed per day and pharmacy. The observation day was equally distributed over the weekdays (Tuesday [five]; Monday, Wednesday, and Thursday [four]; and Friday [three]). The median number of working staff members was two pharmacists, three pharmacy technicians, and one apprentice, respectively.

During the total observation time of 148.1 hours, 1,866 patient contacts were observed, of which 21 resulted in a referral to the physician, 18 in further inquiry by phone or fax with the physician, and eight in a refusal of dispensing. 
Table I Definitions and numbers of observed counseling events by counseling themes and topics of explicit adherence counseling

\begin{tabular}{|c|c|c|c|}
\hline \multirow[t]{2}{*}{ Counseling theme } & \multirow[t]{2}{*}{ Definition } & \multicolumn{2}{|c|}{$\begin{array}{l}\text { Numbers of observed } \\
\text { counseling }\end{array}$} \\
\hline & & Prescription & OTC \\
\hline Administration & $\begin{array}{l}\text { Counseling on basic administration issues (eg, with respect } \\
\text { to meals) }\end{array}$ & 435 & 317 \\
\hline Dose & $\begin{array}{l}\text { Counseling on dosage, dosing times, intervals, and duration } \\
\text { of medication therapy }\end{array}$ & 418 & 226 \\
\hline Effect & Counseling about the effects of the medication & 53 & 221 \\
\hline Adherence & Explicit adherence counseling according to the list of topics & 73 & 57 \\
\hline \multicolumn{4}{|c|}{ Topics of explicit adherence counseling } \\
\hline Morisky question & $\begin{array}{l}\text { Asking the explicit question: "Do you ever forget to } \\
\text { take your medication?" }\end{array}$ & 0 & 0 \\
\hline Adherence & $\begin{array}{l}\text { Directly addressing adherence; assessing the patient's } \\
\text { attitude towards adherence; and mentioning } \\
\text { the importance of adherence }\end{array}$ & 8 & 2 \\
\hline Positive reinforcement & $\begin{array}{l}\text { Acknowledging and encouraging the patients on } \\
\text { efforts for adherent behavior }\end{array}$ & 2 & 0 \\
\hline Motivation & $\begin{array}{l}\text { Assessing motivation of patient to be adherent and, } \\
\text { if necessary, providing support }\end{array}$ & 2 & 2 \\
\hline Organization & $\begin{array}{l}\text { Offering facilitation of medication management through } \\
\text { stick-on labels, diaries, timers, dose-dispensing aids, phone } \\
\text { reminders, organization of social support, etc }\end{array}$ & 9 & 2 \\
\hline Appointment keeping & $\begin{array}{l}\text { Reminding the patient of appointments (with physician, } \\
\text { refill, monitoring) }\end{array}$ & 1 & I \\
\hline Psychological barriers & Among others: forgetfulness; fear of side effects & 3 & 0 \\
\hline Physical barriers & Among others: impaired vision and dexterity; difficulties with swallowing & 4 & 0 \\
\hline Instruction of product & $\begin{array}{l}\text { Providing comprehensive verbal information on use } \\
\text { of the medication in the context of adherence }\end{array}$ & 31 & 18 \\
\hline Written information & Providing written information on the medication & 2 & 5 \\
\hline $\begin{array}{l}\text { Knowledge about } \\
\text { disease/therapy }\end{array}$ & $\begin{array}{l}\text { Explaining the relation between medication therapy } \\
\text { and disease/necessity of therapeutic intervention }\end{array}$ & 10 & 26 \\
\hline (Self-) monitoring & $\begin{array}{l}\text { Instructing the patient about how to perform (self-) monitoring, } \\
\text { including instruction on interpretation of monitored parameters }\end{array}$ & 1 & I \\
\hline
\end{tabular}

Abbreviation: OTC, over the counter.

A total of 1,476 patient contacts included the dispensing of one or more medications, constituting the basis sample for statistical analysis (Figure 1). Of 2,789 products dispensed, $1,742(62.5 \%)$ were on prescription and 1,047 (37.5\%) were "over the counter" (OTC). Counseling was provided to 799 (54.1\%) patients, with 735 (49.8\%) patients counseled about administration, $362(24.5 \%)$ about dose, 267 (18.1\%) about effect, and 99 (6.7\%) about adherence (Figure 2). The total number of observed counseling events was 1,800 , with most patients receiving counseling on two (55.4\%) or three $(21.2 \%)$ themes. Explicit adherence counseling $(n=130)$ mostly included comprehensive instruction (49 [37.7\%]) and counseling on knowledge of disease and medication (36 [27.7\%]) (Table 1). Significantly more patients solely obtaining prescription medication were provided with overall counseling compared with those solely obtaining OTC medication $(57.3 \%$ vs $50.2 \%)\left(\chi^{2}=7.1, P=0.002 ; \mathrm{n}=1,402\right)$. In the same groups, the single theme "effect" was observed significantly more often in patients contacts with the dispensing of OTC than in patients contacts with the dispensing of prescription medication ( $31.3 \%$ vs $6.3 \%)\left(\chi^{2}=148.3, P<0.001 ; \mathrm{n}=1,402\right)$. There was no significant difference in frequency of adherence counseling for prescription vs OTC medication (7.1\% vs 5.9\%) $\left(\chi^{2}=0.9, P=0.17 ; \mathrm{n}=1,402\right)$.

Focusing on the 757 patients solely receiving prescription medication, 421 (55.6\%) had a new prescription, 293 (38.7\%) requested a repeat prescription, $26(3.4 \%)$ had both, and $17(2.2 \%)$ were not specified (Figure 1). The pharmacy staff provided overall counseling to significantly more patients with new prescriptions compared with patients with repeat prescriptions ( $74.1 \%$ vs $33.8 \%)\left(\chi^{2}=115.0, P<0.001 ; \mathrm{n}=714\right)$. There was no significant difference in frequency of adherence counseling in these two groups (new vs repeat prescriptions: $7.1 \%$ vs $4.4 \%$, respectively) $\left(\chi^{2}=2.2, P=0.14\right)$. 


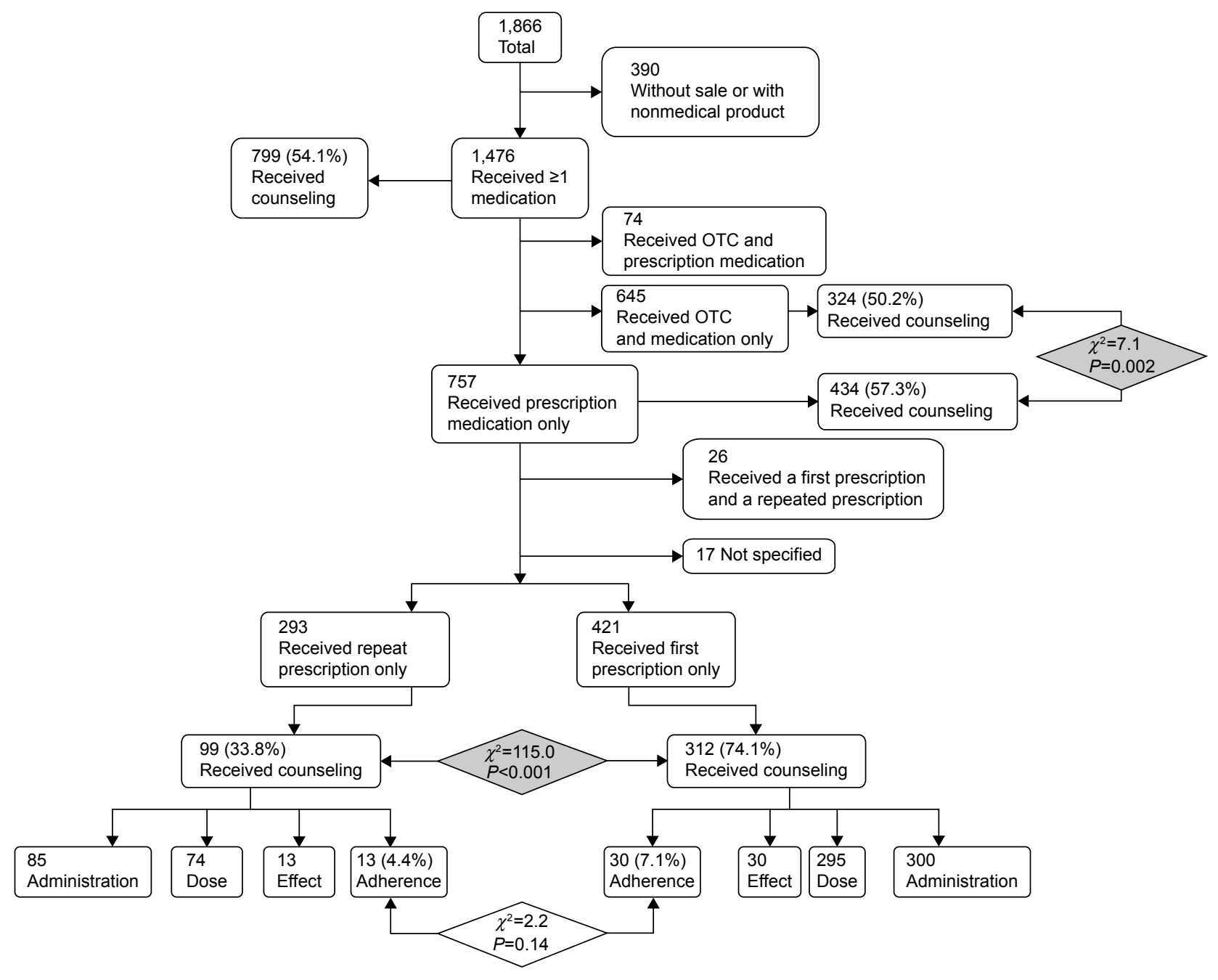

Figure I Patient numbers and allocations by category and themes.

Abbreviation: OTC, over the counter.

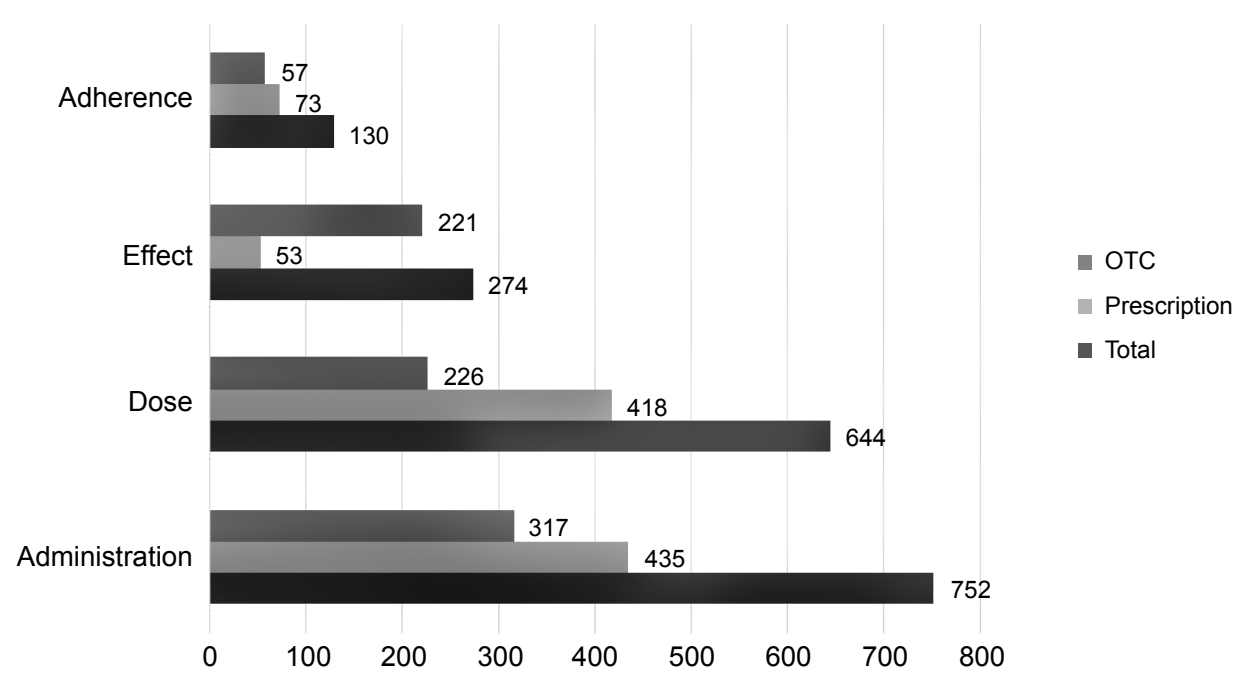

Figure 2 Numbers of observed counseling events about administration, dose, effect, and adherence in total and according to dispensing category (prescription/OTC) Note: $n=1,800$.

Abbreviation: OTC, over the counter. 
Of all patients receiving one or more medications $(n=1,476), 368(24.9 \%)$ were served by a pharmacist, 1,075 (72.8\%) by another staff member (eg, pharmacy technician or apprentice), and 33 (2.2\%) by a combination of both. Significantly more patients received counseling when they were served by a pharmacist compared with other staff members $(62.1 \%$ vs $51.2 \%)\left(\chi^{2}=14.1, P<0.001\right)$. Adherence counseling was provided to twice as many patients when served by a pharmacist compared with other staff members $(10.7 \%$ vs $5.2 \%)\left(\chi^{2}=14.2, P<0.001\right)$.

Of 390 patients who did not receive a medication at the observed contact (eg, buying dose-dispensing aids, ordering out-of-stock medication), 42 (10.8\%) received counseling.

\section{Interview}

Among the 20 community pharmacies, 33 pharmacists participated in the interview (a median of two and range of one to three pharmacists per pharmacy) and were mainly women (69.7\%), with a median age of 41 (range 25-68) years and a median duration of 14 (range 1-43) years after university graduation. They worked with a median of $90 \%$ employment at the community pharmacy (range $40 \%-100 \%$ ). All pharmacists except one reported actively asking patients about their adherence, and $20(60.6 \%)$ did so on a daily basis. Figures 3 and 4 illustrate named triggers and topics of adherence counseling. Barriers included rejection by the patient (15 [45.5\%]), lack of time (12 [36.4\%]), lack of patient data (seven [21.2\%]), lack of checklists and demo material (six [18.2\%]), lack of confidential room (five [15.2\%]), lack of remuneration (three [9.1\%]), and "Other" (19 [57.6\%]).

\section{Discussion}

Counseling was provided to half of the patients receiving one or more medications and occurred more frequently when the medication was on prescription, on a new prescription, or if patients were served by a pharmacist. The content of the counseling mostly included information on medication administration and dose. Only $6.7 \%$ of the patients obtaining medication received explicit adherence counseling, significantly more of them if the pharmacist was involved in the dispensing. However, most

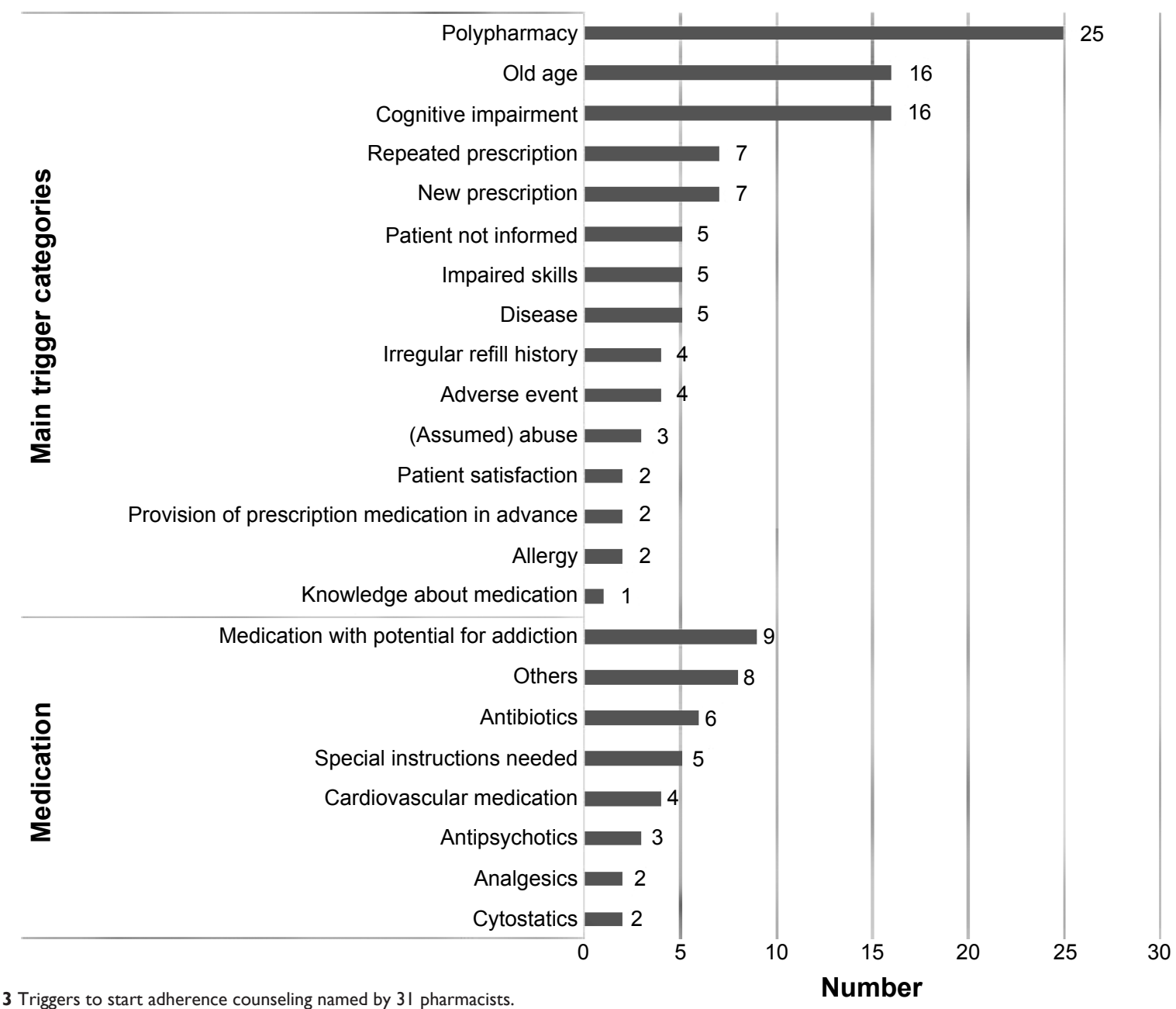

Figure 3 Triggers to start adherence counseling named by 31 pharmacists.

Number 


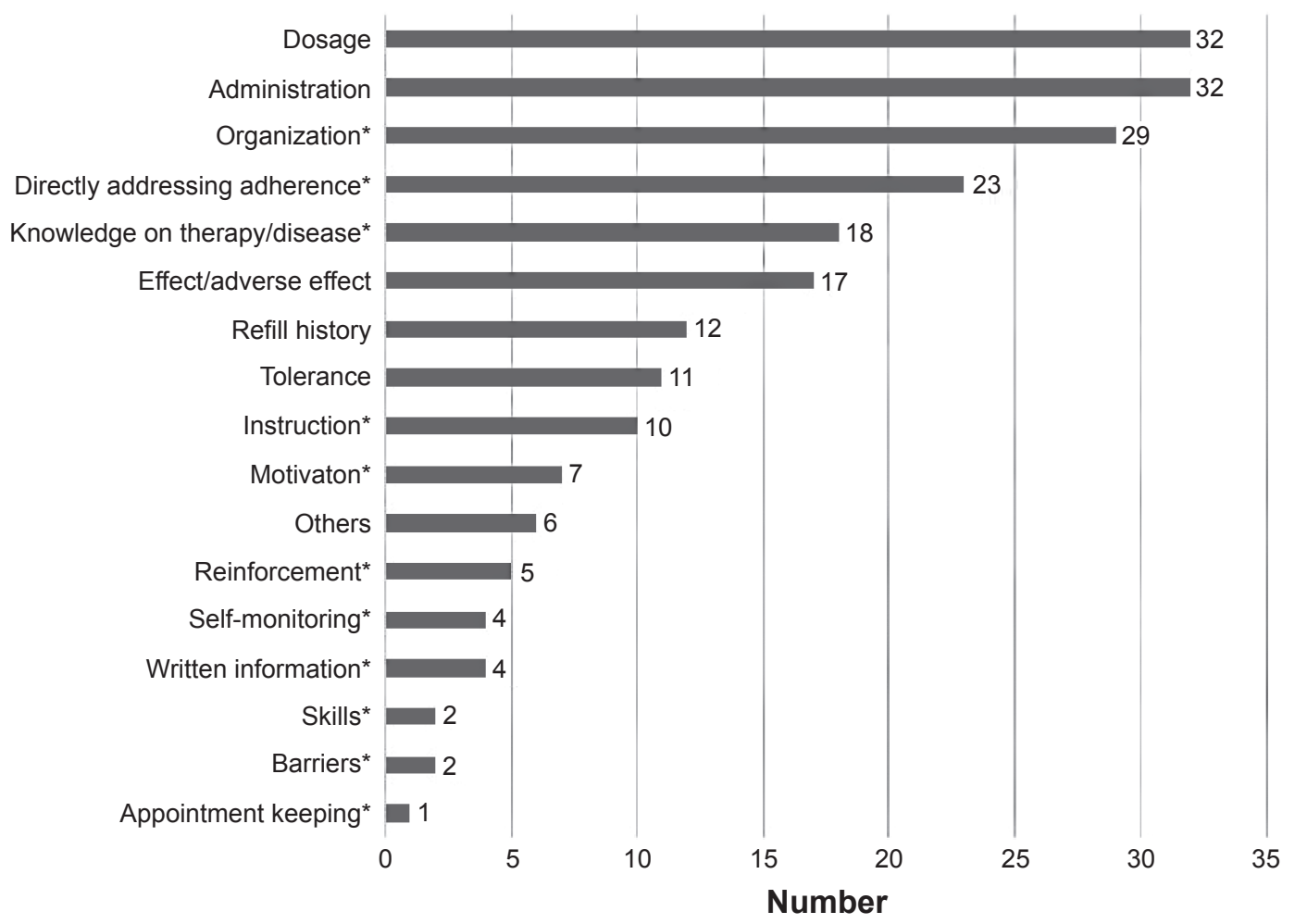

Figure 4 Topics of adherence counseling named by 33 pharmacists.

Notes: The topics marked with asterisks correspond to the predefined topics of explicit adherence counseling in Table I.

pharmacists seemed motivated to provide adherence counseling. They named a lot of triggers but also barriers to start adherence counseling and mostly named topics for adherence counseling, which only implicitly addressed the issue.

Due to easy access, regular patient visits, the possibility to monitor medication refill frequency, and the competences of the pharmacist, the community pharmacy seems to be a predestined place for counseling about adherence. In our study, we showed that if pharmacy staff counseled, they counseled about more than one theme, indicating motivation and assumption of responsibility for safe and effective medication management. If only looking at prescription medication, unsurprisingly, dispensing of first prescriptions largely predominated in the number of patients provided with counseling. A considerable percentage (74.1\%) of these patients were counseled. Apart from the need to ensure the patient's knowledge at first use, the patient filling a first prescription also seems to expect more counseling, which might result in facilitating counseling. ${ }^{30}$ Still, explicit adherence counseling accounts for a very small part in both situations, in the dispensing of a new prescription and in the dispensing of a repeat prescription. Because the pharmacist is able to detect nonadherence in patients with long-term therapy, eg, by analyzing medication refill frequency, we expected adherence counseling to occur more in patients with repeat prescriptions.
Evidence that community pharmacy interventions have been successful in improving health outcomes and adherence have accumulated, ${ }^{5-10,12,31-34}$ and two Cochrane reviews concluded that the pharmacists' cognitive services were beneficial for safe and effective medication use. ${ }^{3,11}$ However, our study confirms results of earlier studies showing that community pharmacies provided limited pharmaceutical care services, ${ }^{17,19,35-37}$ indicating a problem of implementation in daily practice. Studies on counseling in community pharmacies were conducted using patient and pharmacist surveys, observation, and simulated patient visits. ${ }^{38,39}$ They mostly reported on pharmacists' behavior only, with a total counseling rate of $8 \%-100 \% .{ }^{39}$ Similar to our study, predominant categories of counseling were administration and dose, and hence were more product- than patient-centered. ${ }^{22-24,39}$ A large proportion of communications $(26 \%-40 \%)$ between pharmacists and patients was reported to be nonmedical. ${ }^{36,37}$ The only observational study specifically investigating adherence counseling was performed with pharmacy students, who had a lack of specific training in adherence management and of resources, and therefore reported not to address adherence in counseling sessions. ${ }^{40}$ A German study showed that pharmacists documented "evidence of nonadherence" in only $1.6 \%$ of all assessed drug-related problems during patient contacts in community pharmacies, 
indicating that the pharmacists had difficulties in identifying nonadherence. ${ }^{41}$

We showed that pharmacists provided more counseling than pharmacy staff, which confirms the results of another study. ${ }^{35}$ Differences may arise from the more detailed knowledge about therapy and disease, more intense training, and from the assumption of the responsibility for safe and effective medication use by the patients. This knowledge and attitude, however, should be transferred to the whole pharmacy team.

In our study, the comparison of observed counseling practice (observed adherence counseling of 6.7\%) with pharmacists' interview responses $(60.6 \%$ indicated actively approaching patients with adherence issues every day) reveals a discrepancy between our definition and the pharmacists' opinions about the topics of adherence counseling. We defined the topics more explicitly, whereas the most frequently named topics by the pharmacists were implicit. Several problems could arise from the implicit approach. First, the patients might not understand the purpose of the counseling and reject it. Second, while some unintentional nonadherence problems might be clarified with counseling on administration and dose, intentional nonadherence might be completely overlooked. Literature has described habits of pharmacists mainly asking standardized questions, eg, "Do you have any questions?"; at the same time, authors have suggested a more considerate and individualized approach according to patients' needs, and the necessity of engaging patients in counseling. ${ }^{24,42,43}$ Such an approach would include a more direct addressing of adherence. Further, almost all topics on our predefined list of explicit adherence counseling were named by the pharmacists, indicating that they were familiar with most of the topics, though less frequently addressed them during the observed patient contacts.

The most frequently reported barrier was rejection of the offered counseling by the patients. This has also been shown in other studies, with $41 \%-63 \%$ of patients declining offered counseling. ${ }^{30,36}$ Expectations of patients have been shown to not coincide with the recent development of the pharmacist's role. ${ }^{43,44}$ Qualitative studies reported patient tendency to rely solely on the physicians, recommendations and to deny the pharmacists' competences. ${ }^{45,46}$ This attitude persisted even in patient-centered consultations ${ }^{47}$ and was confirmed by a recent study that collected data over 15 years. ${ }^{48}$

It seems logical that patients with prescribed medications obtain more counseling, on one hand because the medication plan usually is more complex, including long- and short-term medication for serious diseases, and hence counseling might be more relevant. On the other hand, the counseling about prescribed medication is remunerated by a medication tax of CHF 4.20 (= US\$ 4.60) per prescribed item. Nevertheless, lack of adequate remuneration was only named by $9.1 \%$ of the pharmacists as barrier for adherence counseling. Remarkably, counseling was also given without product sale.

Apart from the structural factors discussed above, several procedure-related factors were identified, which hinder pharmacists in counseling, and patients in asking questions. Time constraints pose such a barrier. ${ }^{40,48-50}$ However, surveys on pharmacists' activities revealed that pharmacists were mainly occupied with traditional product-centered activities, such as business management, logistics, and product assembly, than with patient-centered activities, like counseling. ${ }^{18-21}$ In our study, we observed that pharmacists had fewer patient contacts in relation to their presence compared with the rest of the staff. Consequently, the problem could be designated as time mismanagement, and reconsiderations of staffing and of assignment of responsibilities might be a solution.

Another barrier to patient-centered, individualized counseling is the lack of privacy, named by the pharmacists in our study and also reported elsewhere. ${ }^{35,45,50}$ Most people certainly are uncomfortable discussing their sensitive health problems next to a line of others at the counter. The traditional conceptualization of the pharmacy accommodations reminds patients more of a shop ${ }^{46}$ than of a health care center and hence is not supportive in promoting counseling.

The limitations of our study firstly include the restriction to one region in Switzerland. Secondly, the methodology of observation has been reported to yield variable results but a more holistic picture of counseling practice. ${ }^{39}$ We chose a minimally obtrusive method to observe the counseling, in order to prevent the introduction of biases. However, the open approach of the pharmacies and the presence of an observer could have triggered pharmacy staff to engage more in counseling practice than usual (Hawthorne effect). ${ }^{51}$ Thirdly, the ad hoc coding without review by a second person could have limited the results' reliability. Fourthly, due to the observational setting, we could not evaluate the rate of overall offered counseling. With the most named barrier for adherence counseling being the rejection of counseling by the patients, we can assume higher counseling rates at higher acceptance of counseling.

\section{Conclusion}

The unique position of the community pharmacy in the health care chain and the competencies of pharmacists make the community pharmacy a predestined place for medication and 
adherence counseling. Pharmacists are motivated to provide counseling but experience several structural and procedural barriers in delivering it. In our study, half of patients collecting one or more medications received counseling, which was predominantly product-centered, and only $6.7 \%$ of the patients received adherence counseling. This study revealed insufficient knowledge and gaps in the provision of explicit adherence counseling by pharmacists. Future studies should explore the pharmacist-patient interaction in depth and clarify how barriers to adherence counseling in the community pharmacy can be overcome.

\section{Acknowledgments}

We would like to thank Irene Rüfenacht (MSc Pharm) for her participation in conceptualization of the project and data collection, and Gülistan Karatas (MSc Pharm) for data entry.

\section{Author contributions}

All authors participated in conceptualizing the study. FB analyzed data and drafted the manuscript. IA and KEH revised the manuscript critically for intellectual content.

\section{Disclosure}

The authors report no conflicts of interest in this work.

\section{References}

1. Allemann SS, van MilJW, BotermannL, Berger K, Griese N, Hersberger KE. Pharmaceutical care: the PCNE definition 2013. Int J Clin Pharm. 2014;36(3):544-555.

2. Chisholm-Burns MA, Kim Lee J, Spivey CA, et al. US pharmacists' effect as team members on patient care: systematic review and meta-analyses. Med Care. 2010;48(10):923-933.

3. Ryan R, Santesso N, Lowe D, et al. Interventions to improve safe and effective medicines use by consumers: an overview of systematic reviews. Cochrane Database Syst Rev. 2014;4:CD007768.

4. Joint FIP/WHO Guidelines on GPP: Standards for Quality of Pharmacy Services. World Health Organisation; Fédération Internationale Pharmaceutique; 2011. Available from: http://www.fip.org/www/uploads/database_file.php?id=331\&table_id=, 2014. Accessed January 8, 2015.

5. Obreli-Neto PR, Guidoni CM, de Oliveira Baldoni A, et al. Effect of a 36-month pharmaceutical care program on pharmacotherapy adherence in elderly diabetic and hypertensive patients. Int J Clin Pharm. 2011;33(4):642-649.

6. van Boven JF, Stuurman-Bieze AG, Hiddink EG, Postma MJ, Vegter S. Medication monitoring and optimization: a targeted pharmacist program for effective and cost-effective improvement of chronic therapy adherence. J Manag Care Pharm. 2014;20(8):786-792.

7. Pringle JL, Boyer A, Conklin MH, McCullough JW, Aldridge A. The Pennsylvania Project: pharmacist intervention improved medication adherence and reduced health care costs. Health Aff (Millwood). 2014;33(8):1444-1452.

8. Rubio-Valera M, Serrano-Blanco A, Magdalena-Belío J, et al. Effectiveness of pharmacist care in the improvement of adherence to antidepressants: a systematic review and meta-analysis. Ann Pharmacother. 2011;45(1):39-48.

9. Jarab AS, Alqudah SG, Khdour M, Shamssain M, Mukattash TL. Impact of pharmaceutical care on health outcomes in patients with COPD. Int $J$ Clin Pharm. 2012;34(1):53-62.
10. Lee JK, Grace KA, Taylor AJ. Effect of a pharmacy care program on medication adherence and persistence, blood pressure, and lowdensity lipoprotein cholesterol: a randomized controlled trial. JAMA. 2006;296(21):2563-2571.

11. Nkansah N, Mostovetsky O, Yu C, et al. Effect of outpatient pharmacists' non-dispensing roles on patient outcomes and prescribing patterns. Cochrane Database Syst Rev. 2010;7:CD000336.

12. van Dalem J, Krass I, Aslani P. Interventions promoting adherence to cardiovascular medicines. Int J Clin Pharm. 2012;34(2):295-311.

13. Chandra A, Malcolm N, Fetters M. Practicing health promotion through pharmacy counseling activities. Health Promot Pract. 2003;4(1):64-71.

14. Taitel M, Jiang J, Rudkin K, Ewing S, Duncan I. The impact of pharmacist face-to-face counseling to improve medication adherence among patients initiating statin therapy. Patient Prefer Adherence. 2012;6:323-329.

15. Clifford S, Barber N, Elliott R, Hartley E, Horne R. Patient-centred advice is effective in improving adherence to medicines. Pharm World Sci. 2006;28(3):165-170.

16. Zolnierek KB, Dimatteo MR. Physician communication and patient adherence to treatment: a meta-analysis. Med Care. 2009;47(8): 826-834.

17. Hughes CM, Hawwa AF, Scullin C, et al. Provision of pharmaceutical care by community pharmacists: a comparison across Europe. Pharm World Sci. 2010;32(4):472-487.

18. Bell HM, McElnay JC, Hughes CM. A self-reported work sampling study in community pharmacy practice. Pharm World Sci. 1999; 21(5):210-216.

19. McCann L, Hughes CM, Adair CG. A self-reported work-sampling study in community pharmacy practice: a 2009 update. Pharm World Sci. 2010;32(4):536-543.

20. Schommer JC, Pedersen CA, Doucette WR, Gaither CA, Mott DA. Community pharmacists' work activities in the United States during 2000. J Am Pharm Assoc (Wash). 2002;42(3):399-406.

21. Davies JE, Barber N, Taylor D. What do community pharmacists do?: results from a work sampling study in London. Int J Pharm Pract. 2014;22(5):309-318.

22. Hassell K, Noyce P, Rogers A, Harris J, Wilkinson J. Advice provided in British community pharmacies: what people want and what they get. J Health Serv Res Policy. 1998;3(4):219-225.

23. Chong WW, Aslani P, Chen TF. Pharmacist-patient communication on use of antidepressants: a simulated patient study in community pharmacy. Res Social Adm Pharm. 2014;10(2):419-437.

24. Sleath B. Pharmacist-patient relationships: authoritarian, participatory, or default? Patient Educ Couns. 1996;28(3):253-263.

25. Tarifvertrag (LOA IV) zwischen dem Schweizerischen Apothekerverband (pharmaSuisse) und santésuisse - Die Schweizer Krankenversicherer (santésuisse) [Labor agreement between the Swiss Pharmacist Association and the Association of Swiss Health Insurances]. Liebefeld/ Solothurn; 2009 [cited January 26, 2015]. Available from: http://www. pharmasuisse.org/data/Oeffentlich/de/Themen/Tarifvertrag_LOA-IV_ def_d_09-03-6.pdf. Accessed January 26, 2015. German.

26. Guignard E, Bugnon O. Pharmaceutical care in community pharmacies: practice and research in Switzerland. Ann Pharmacother. 2006;40(3):512-517.

27. Eichenberger PM, Lampert ML, Kahmann IV, van Mil JW, Hersberger KE. Classification of drug-related problems with new prescriptions using a modified PCNE classification system. Pharm World Sci. 2010;32(3):362-372.

28. Mengiardi S, Tsakiris DA, Molnar V, et al. Impact of pharmaceutical care on self-administration of outpatient low-molecular-weight heparin therapy. Pharmacol Pharm. 2014;5(4):372-385.

29. Haynes RB, McDonald HP, Garg AX. Helping patients follow prescribed treatment: clinical applications. JAMA. 2002;288(22):2880-2883.

30. Puspitasari HP, Aslani P, Krass I. Pharmacists' and consumers' viewpoints on counselling on prescription medicines in Australian community pharmacies. Int J Pharm Pract. 2010;18(4):202-208. 
31. Clifford RM, Davis WA, Batty KT, Davis TM; Fremantle Diabetes Study. Effect of a pharmaceutical care program on vascular risk factors in type 2 diabetes: the Fremantle Diabetes Study. Diabetes Care. 2005;28(4):771-776.

32. Paulós CP, Nygren CE, Celedón C, Cárcamo CA. Impact of a pharmaceutical care program in a community pharmacy on patients with dyslipidemia. Ann Pharmacother. 2005;39(5):939-943.

33. Hohmann C, Klotz JM, Radziwill R, Jacobs AH, Kissel T. Pharmaceutical care for patients with ischemic stroke: improving the patients quality of life. Pharm World Sci. 2009;31(5):550-558.

34. Roughead EE, Semple SJ, Vitry AI. Pharmaceutical care services: a systematic review of published studies, 1990 to 2003, examining effectiveness in improving patient outcomes. Int J Pharm Pract. 2005;13(1):53-70.

35. Kimberlin CL, Jamison AN, Linden S, Winterstein AG. Patient counseling practices in U.S. pharmacies: effects of having pharmacists hand the medication to the patient and state regulations on pharmacist counseling. J Am Pharm Assoc (2003). 2011;51(4):527-534.

36. Kaae S, Mygind A, Saleem S. A characterization of the current communication patterns in Danish community pharmacies - an observational study. Res Social Adm Pharm. 2013;9(6):958-964.

37. Olsson E, Ingman P, Ahmed B, Kälvemark Sporrong S. Pharmacistpatient communication in Swedish community pharmacies. Res Social Adm Pharm. 2014;10(1):149-155.

38. Schommer JC, Sullivan DL, Wiederholt JB. Comparison of methods used for estimating pharmacist counseling behaviors. J Pharm Technol. 1994;10(6):261-268.

39. Puspitasari HP, Aslani P, Krass I. A review of counseling practices on prescription medicines in community pharmacies. Res Social Adm Pharm. 2009;5(3):197-210.

40. Mangan MN, Powers MF, Lengel AJ. Student pharmacists' perceptions of barriers to medication adherence counseling. J Pharm Pract. 2013;26(4):376-381.
41. Nicolas A, Eickhoff C, Griese N, Schulz M. Drug-related problems in prescribed medicines in Germany at the time of dispensing. Int J Clin Pharm. 2013;35(3):476-482.

42. Kaae S, Traulsen JM, Nørgaard LS. Challenges to counseling customers at the pharmacy counter - why do they exist? Res Social Adm Pharm. 2012;8(3):253-257.

43. Shah BK, Chewning B. Concordance between observer reports and patient survey reports of pharmacists' communication behaviors. Res Social Adm Pharm. 2011;7(3):272-280.

44. Renberg T, Wichman Törnqvist K, Kälvemark Sporrong S, Kettis Lindblad A, Tully MP. Pharmacy users' expectations of pharmacy encounters: a Q-methodological study. Health Expect. 2011;14(4): 361-373.

45. Cocohoba J, Comfort M, Kianfar H, Johnson MO. A qualitative study examining HIV antiretroviral adherence counseling and support in community pharmacies. J Manag Care Pharm. 2013;19(6):454-460.

46. Kaae S, Traulsen JM, Nørgaard LS. Customer interest in and experience with various types of pharmacy counselling - a qualitative study. Health Expect. 2014;17(6):852-862.

47. Salter C, Holland R, Harvey I, Henwood K. "I haven't even phoned my doctor yet." The advice giving role of the pharmacist during consultations for medication review with patients aged 80 or more: qualitative discourse analysis. BMJ. 2007;334(7603):1101.

48. Schommer JC, Gaither CA. A segmentation analysis for pharmacists' and patients' views of pharmacists' roles. Res Social Adm Pharm. 2014;10(3):508-528.

49. Schommer JC, Wiederholt JB. A field investigation of participant and environment effects on pharmacist-patient communication in community pharmacies. Med Care. 1995;33(6):567-584.

50. Schommer JC, Wiederholt JB. Pharmacists' perceptions of patients' needs for counseling. Am J Hosp Pharm. 1994;51(4):478-485.

51. Delgado-Rodríguez M, Llorca J. Bias. J Epidemiol Community Health. 2004;58(8):635-641.
Patient Preference and Adherence

\section{Publish your work in this journal}

Patient Preference and Adherence is an international, peer-reviewed, open access journal that focuses on the growing importance of patient preference and adherence throughout the therapeutic continuum. Patient satisfaction, acceptability, quality of life, compliance, persistence and their role in developing new therapeutic modalities and compounds to optimize

\section{Dovepress}

clinical outcomes for existing disease states are major areas of interest for the journal. This journal has been accepted for indexing on PubMed Central. The manuscript management system is completely online and includes a very quick and fair peer-review system, which is all easy to use. Visit http://www. dovepress.com/testimonials.php to read real quotes from published authors. 